\title{
The Impact of Active Learning on Students' Academic Performance
}

\author{
Chadia A. Aji, M. Javed Khan \\ Tuskegee University, Tuskegee, Alabama, USA \\ Email: caji@tuskegee.edu,mjkhan@tuskegee.edu
}

How to cite this paper: Aji, C.A. and Khan, M.J. (2019) The Impact of Active Learning on Students' Academic Performance. Open Journal of Social Sciences, 7, 204-211.

https://doi.org/10.4236/jss.2019.73017

Received: December 5, 2018

Accepted: March 10, 2019

Published: March 13, 2019

\begin{abstract}
The empirical assessments of the traditional teaching approach of lecturing in the undergraduate classroom indicate its ineffectiveness in the learning process. This traditional pedagogy has been identified as one of the major reasons adversely impacting student engagement and motivation, especially in the science, technology, engineering and mathematics (STEM) fields. Research on learning provides strong evidence that active-learning can have a positive impact on student learning outcomes. The biggest challenge with incorporating active-learning strategies in the classroom is the time constraint of the traditional class period. One of the approaches that is finding increasing acceptance among educators is the use of the flipped classroom. This paper shares details of the impact of active-learning on academic achievement of students from groups underrepresented in STEM in introductory mathematics and aerospace engineering courses. The results indicated that the performance of students who took the courses with the active learning improved.
\end{abstract}

\section{Keywords}

Active Learning, Flipped Classroom, STEM, Math, Aerospace Engineering

\section{Introduction}

The $20^{\text {th }}$ century and the last almost two decades of the $21^{\text {st }}$ century have seen an exponential increase in discoveries and inventions that have found extensive use globally and have spawned ever expanding job and career opportunities. The younger population (25 years and below) is a major consumer of the technological products developed as a result of these scientific discoveries and inventions. However, despite the very obvious advantages of an education and expertise in a science, technology, engineering and mathematics (STEM) subject, the U.S. STEM work force is not growing at a rate to fill the available and projected jobs. 
The reason for this problem is well recognized as the "leaky" STEM education pipeline.

Several constructs have been identified that impact persistence, retention and academic success. These constructs include self-efficacy, motivation and engagement. Bandura [1] defined perceived self-efficacy as "belief in one's capabilities to organize, and execute the courses of action required to produce given attainments, the perception to do tasks and achieve goals". Motivation is the result of psychological processes driven intrinsically or through external influences that "direct, energize and maintain action" towards a goal [2]. Deeper learning has been linked to cognitive engagement of learners [3]. However, these constructs are not independent but play a complex interactive role in the academic process. The effect of self-efficacy on behavioral, cognitive and motivational engagement has been reported by Linnenbrink and Pintrich [4]. Self-efficacy has been identified by Schunk and Mullen [5] as a key variable that influences motivation and engagement in the classroom. A meta-analysis of 114 studies by Stajkovic and Luthans [6] found a strong correlation between self-efficacy and performance. A correlation between motivation and students' perception of progress and learning has also been reported by Schunk [7]. Yusuf [8] found a strong correlation between self-efficacy, achievement-motivation and self-learning strategies in his study of 300 undergraduate students. A major reason for school dropout is underachievement resulting from low academic motivation [5]. Thus, student engagement with the learning materials is an important aspect for student success. Handelsman et al. [9] identified skills, participation/interaction, emotional, and achievement as four reliable dimensions of student engagement at the course level. Learning environments that emphasize these dimensions are gaining popularity. Problem-based learning and project-based learning which are active-learning pedagogies are examples of learning environments that promote student engagement [10] [11] [12] [13]. These active-learning approaches fall under the category of inductive learning [14].

Active-learning "engages students in the process of learning through activities and/or discussion in class, as opposed to passively listening to an expert. It emphasizes higher-order thinking and often involves group work" [15]. Active learning provides opportunities for meaningful academic activities which has a positive impact on retention especially of first year students [16]. The classroom is therefore rapidly transitioning from a teaching-centered to a learning-centered environment as a result of a recognition of the positive impact of active-learning. However, the biggest challenge to incorporating active learning in the classroom is the duration of the class period. One of the approaches to freeing up class time for active-learning is the "flipped classroom". In the flipped classroom approach, the "lecture" is moved out of the classroom in the form of engaging audio-video enhanced learning material for students to study before coming to class. The classroom time can now be effectively dedicated to carefully designed hands-on activities that strengthen the concepts, provide opportunities to move towards skills automaticity and enhance critical thinking skills. An increasing body of 
empirical evidence is pointing towards the effectiveness of the flipped classroom [17]-[24]. Flipped classrooms have been reported to enhance problem-solving capability [25] [26] [27] [28], improve academic performance and overall grades [26] [29]-[35], and increase retention [26] [33] [36].

The effectiveness of the flipped classroom in allowing the incorporation of active-learning in the classroom reported in the research literature was the motivation for this research. This paper provides details of the impact of active-learning on academic achievement of students who were primarily first-generation college students and were from groups underrepresented in STEM.

\section{Method}

Active-learning strategies were implemented in lower level math and aerospace engineering courses. These courses were Pre-Calculus Algebra, and Pre-Calculus Algebra and Trigonometry, Introduction to Aerospace Engineering, and Aerodynamics-I. The learning materials were posted a week prior to the class meeting. The class size is 25 to 30 students per class. These learning materials consisted of annotated power points, videos explaining the basic concepts. The content of the online pre-class learning materials corresponded to the knowledge and comprehension levels of Bloom's Taxonomy [37]. These videos were designed such that the typical content of a traditional lecture which usually is no more than 20 - 30 minutes was provided in 2 - 3 videos of a maximum of 10 minutes each. The materials in the videos consisted of annotated PowerPoint explanations, pictures, embedded animations etc. For-credit short quizzes to test some of the basics that were explained in the videos were part of the online pre-class resources. Students were expected to watch the videos and required to take the short online quizzes. The objective of the quizzes was twofold. Firstly, the quizzes consist of simple questions over the pre-class materials (mainly videos) to make sure that students are ready for the in-class active learning to reinforce these concepts. Secondly and more importantly, the performance on these quizzes would provide information on the level of understanding and challenges faced by the students in understanding these concepts.

The class meeting time was then utilized to engage students in activities that were on the higher levels (application, analysis) on Bloom's Taxonomy [37]. These activities included group work which facilitated peer-to-peer learning, problem-solving, explaining concepts/problem solution to peers etc. The performance on the online pre-class quizzes was used to provide in-class work to clarify and strengthen the concepts that students experienced difficulty with. Other techniques such "Jeopardy" games were used to engage students in learning the concepts.

The research design was a between-group quasi-experimental design. The intervention group consisted of students who were enrolled in the flipped courses that afforded active-learning interventions, while the control group consisted of students who had taken the courses in a traditional format. 
The academic performance of students who were enrolled in the flipped classes (intervention group) was compared at the end of the semester with performance of students who were enrolled in traditional courses (control group) in the previous semesters. Both groups were taught by the same faculty to minimize the teaching variability.

The participants in the intervention group were: Pre-Calculus Algebra (Math 107; $\mathrm{n}=21$ ), Pre-Calculus Algebra and Trigonometry (Math 110; $\mathrm{n}=21$ ); Introduction to Aerospace Engineering (AENG 100; $n=30$ ) and Aerodynamics-1 (AENG 244; $\mathrm{n}=17)$.

\section{Results and Discussion}

The academic achievement of the students in the active-learning classroom (with flipped delivery) in Math 107 was compared with the performance of the students in the traditional class. The data (Figure 1) shows that the passing rate (with $\mathrm{A}, \mathrm{B}$, and $\mathrm{C}$ grades) was $61 \%$ as compared to traditional classroom where the pass percentage (with $A, B$, and C grades) was only $40 \%$.

The comparison of performance in Math 110 showed a similar trend (Figure 2). The passing rate (with $\mathrm{A}, \mathrm{B}$, and $\mathrm{C}$ grades) in the active-learning classroom (flipped) was $81 \%$ as compared to the traditional classroom where the passing rate was $67 \%$.
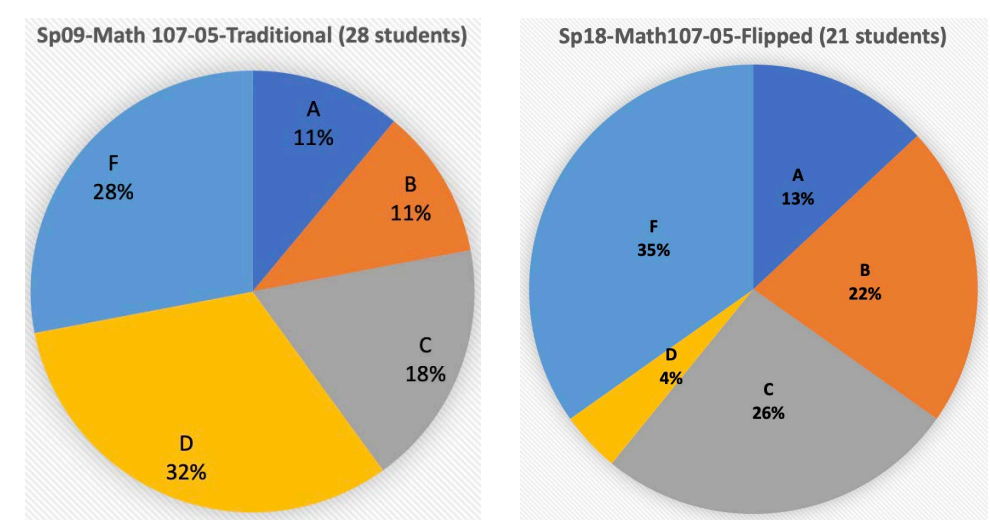

Figure 1. Comparison of performance in Math 107.
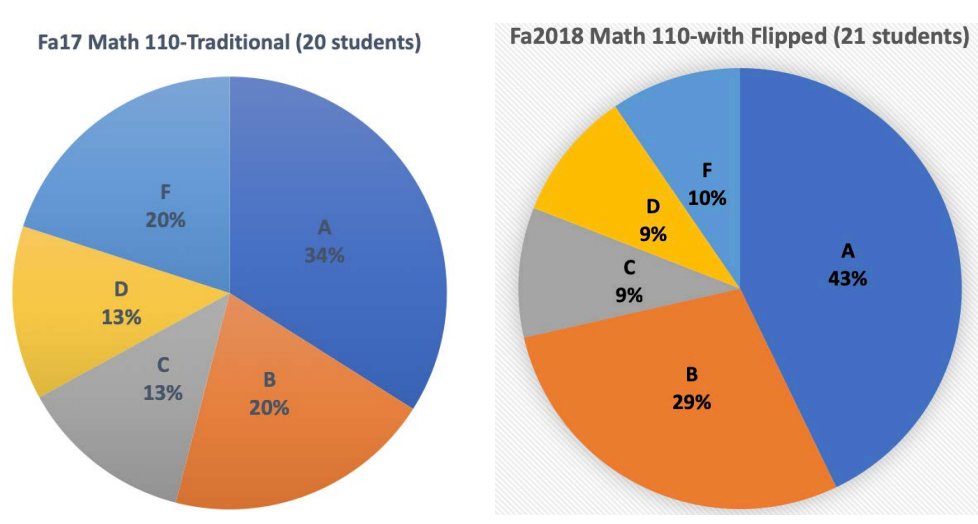

Figure 2. Comparison of performance in Math 110-pre-calculus alg. \& trig. 
A comparison between the active-learning classroom (with flipped) and traditional classroom also indicated that the active-learning pedagogy had a positive impact on the academic achievement of students in aerospace engineering as well. While the passing rate for the Introduction to Aerospace Engineering (AENG 100) course in both modes of delivery was about the same $(100 \%$ for flipped and $89 \%$ for traditional), the students in the active-learning classroom had a higher academic achievement rate with $64 \%$ of the students achieving an A-grade as compared to $36 \%$ in the traditional classroom (Figure 3 ).

The students of the active-learning (with flipped) Aerodynamics-I course (AENG 244) also performed better as compared to the students in the traditional classroom (Figure 4). The passing rate for the flipped classroom was $100 \%$ while the traditional class had a passing rate of $89 \%$. It can be observed that in the flipped class, $29 \%$ achieved an A grade as compare to $16 \%$ in the traditional classroom.

As indicated by the results, active-learning (with the flipped delivery) in the lower level courses in math and aerospace engineering not only resulted in increased success rates but also in higher academic performance of students.

\section{Future Work}

Additional lower level courses in math and aerospace engineering are being designed with the active learning approach. The success, effectiveness and best
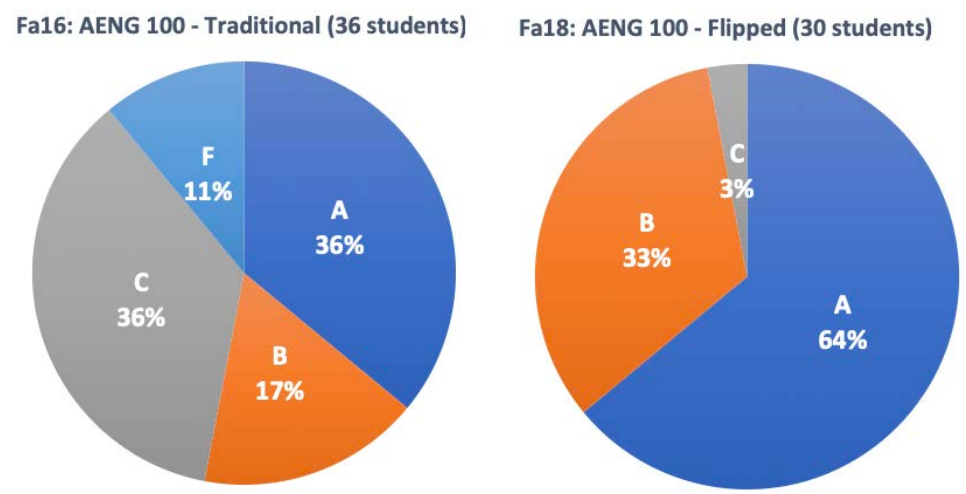

Figure 3. Performance in AENG 100-introduction to aerospace eng.

Fa 17-AENG 244 Traditional (19 std)

Fa 18-AENG 244 Flipped (17 std)
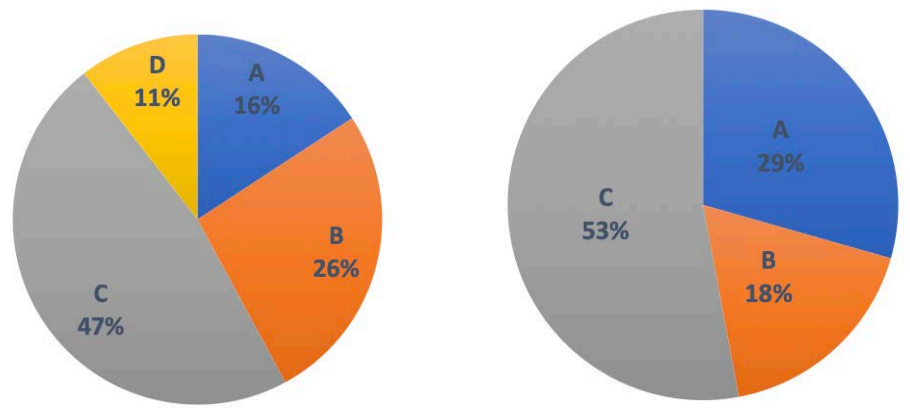

Figure 4. Comparison of AENG 244-aerodynamics-1. 
practices will be shared with faculty to motivate them to consider using this pedagogical approach to positively impact student learning outcomes, success and persistence in science, mathematics and engineering majors.

\section{Acknowledgements}

This work is supported by the Improving Undergraduate STEM Education (IUSE) program of the National Science Foundation (NSF), Grant\# 1712156.

\section{Conflicts of Interest}

The authors declare no conflicts of interest regarding the publication of this paper.

\section{References}

[1] Bandura, A. (1997) Self-Efficacy: The Exercise of Control. W.H. Freeman Co.

[2] Grant, A.M. and Shin, J. (2012) Work Motivation: Directing, Energizing, and Maintaining Effort (and Research). The Oxford Handbook of Human Motivation Ryan, R.M., Ed.

[3] Craik, F.I.M. and Lockhart, R.S. (1972) Levels of Processing: A Framework for Memory Research. Journal of Verbal Learning and Verbal Behavior, 11, 671-684. https://doi.org/10.1016/S0022-5371(72)80001-X

[4] Linnenbrink, E.A. and Pintrich, P.R. (2003) The Role of Self-Efficacy Beliefs in Student Engagement and Learning in the Classroom. Reading and Writing Quarterly, 19, 119-137. https://doi.org/10.1080/10573560308223

[5] Schunk, D.H. and Mullen, C.A. (2012) Self-Efficacy as an Engaged Learner. In: Christenson, S.J., Reschly, A.L. and Wylie, C., Eds., Handbook of Research on Student Engagement, Springer, New York, 219-235.

https://doi.org/10.1007/978-1-4614-2018-7_10

[6] Stajkovic, A. and Luthans, F. (1998) Self-Efficacy and Work-Related Performance: A Metaanalysis. Psychological Bulletin, 124, 240-261.

https://doi.org/10.1037/0033-2909.124.2.240

[7] Schunk, H.D. (1991) Self-Efficacy and Academic Motivation. Journal of Educational Psychologist, 26.

[8] Yusuf, M. (2011) Investigating Relationship between Self-Efficacy, Achievement Motivation, and Self-regulated Learning Strategies of Undergraduate Students. A study of Integrated Motivational Models. Procedia Social and Behavioral Sciences, 15, 2623-2626. https://doi.org/10.1016/j.sbspro.2011.04.158

[9] Handelsman, M.M., Briggs, W.L, Sullivan, N. and Towler, A. (2005) A Measure of College Student Course Engagement. The Journal of Educational Research, 98. https://doi.org/10.3200/JOER.98.3.184-192

[10] Silberman, M. (1996) Active Learning: 101 Strategies to Teach Any Subject. Prentice-Hall.

[11] Duch, B., Groh, S. and Allen, D. (2001) The Power of Problem-Based Learning: A Practical 'How To' for Teaching Undergraduate Courses in Any Discipline. Stylus Publishing LLC.

[12] McConnell, D., Steers, D. and Owens, K. (2003) Assessment and Active Learning Strategies for Introductory Geology Courses, Journal of Geoscience Education, 51, 
205-216. https://doi.org/10.5408/1089-9995-51.2.205

[13] Prince, M. (2004) Does Active Learning Work? A Review of Research. Journal of Engineering Education, 93, 223-231. https://doi.org/10.1002/j.2168-9830.2004.tb00809.x

[14] Prince, M. and Felder, R.M. (2006) Inductive Teaching and Learning Methods, Journal of Engineering Education, 95, 123-138. https://doi.org/10.1002/j.2168-9830.2006.tb00884.x

[15] Freeman, et al. (2014) PNAS, 111. https://www.ncbi.nlm.nih.gov/pmc/articles/PMC4060654/

[16] Kuh, G.D., Cruce, T.M., Shoup, R., Kinzie, J. and Gonyea, R.M. (2008) Unmasking the Effects of Student Engagement on First-Year College Grades and Persistence, The Journal of Higher Education, 79, 540-563. https://doi.org/10.1080/00221546.2008.11772116

[17] Berrett, D. (2012) How 'Flipping' the Classroom Can Improve the Traditional Lecture. Chronicle of Higher Education.

[18] Amresh, A., Carberry, A. and Femiani, J. (2013) Evaluating the Effectiveness of Flipped Classrooms for Teaching CS1. Proceedings-Frontiers in Education Conference, October 2013. https://doi.org/10.1109/FIE.2013.6684923

[19] Lee, A., Zhu, H. and Middleton, J.A. (2016) A Study of the Flipped Classroom and Its Effectiveness in Flipping Thirty Percent of the Course Content. ASEE $123^{\text {rd }}$ Annual Conference and Exposition, New Orleans, 26-28 June 2016.

[20] Nwosisi, C., Ferreira, A., Rosenberg, W. and Walsh, I.K. (2016) A Study of the Flipped Classroom and Its Effectiveness in Flipping Thirty Percent of the Course Content. International Journal of Information and Education Technology, 6. https://doi.org/10.7763/IJIET.2016.V6.712

[21] Zainuddin, Z. and Halili, S.H. (2016) Flipped Classroom Research and Trends from Different Fields of Study. International Review of Research in Open and Distributed Learning, 17. https://doi.org/10.19173/irrodl.v17i3.2274

[22] Chen, F., Lui, A.M. and Martinelli, S.M. (2017) A Systematic Review of the Effectiveness of Flipped Classrooms in Medical Education. Med Educ, 51, 585-597. https://doi.org/10.1111/medu.13272

[23] Gillette, C., Rudolph, M., Kimble, C., Rockich-Winston, N., Smith, L. and Broedel-Zaugg, K. (2018) A Meta-Analysis of Outcomes Comparing Flipped Classroom and Lecture. American Journal of Pharmaceutical Education, 82.

[24] Cabi, E. (2018) The Impact of the Flipped Classroom Model on Students' Academic Achievement. International Review of Research in Open and Distributed Learning, 19. http://www.irrodl.org/index.php/irrodl/article/view/3482/4647 https://doi.org/10.19173/irrodl.v19i3.3482

[25] Park, J.H. and Han, T.I. (2018) The Effect of Flipped Learning on Problem-Solving Capability in Software Education. International Journal of Information and Education Technology, 8, 304-307. https://doi.org/10.18178/ijiet.2018.8.4.1052

[26] Chis, A.E., Moldovan, A.-N., Murphy, L., Pathak, P. and Muntean, C.H. (2018) Investigating Flipped Classroom and Problem-Based Learning in a Programming Module for Computing Conversion Course. Educational Technology \& Society, 21, 232-247.

[27] Iwaniec, M., Simmonds, T. and Swan, Z. (2017) A Practical Case Study Exploring How Flipped Learning Affects the Development of Problem Solving Skills in Two Different Disciplines. Compass: Journal of Learning and Teaching, 10. 
[28] Wilson, S.G. (2013) The Flipped Class: A Method to Address the Challenges of an Undergraduate Statistics Course. Teaching of Psychology, 40, 193-199. https://doi.org/10.1177/0098628313487461

[29] Koo, C.L., Demps, E.L., Farris, C., Bowman, J.D., Panahi, L. and Boyle, P. (2016) Impact of Flipped Classroom Design on Student Performance and Perceptions in a Pharmacotherapy Course. Am J Pharm Educ, 80, 33. https://doi.org/10.5688/ajpe80233

[30] Pavanelli, R. (2018) The Flipped Classroom: A Mixed Methods Study of Academic Performance and Student Perception in EAP Writing Context. International Journal of Language and Linguistics, 5.

[31] Seery, M.K. (2015) Flipped Learning in Higher Education Chemistry: Emerging Trends and Potential Directions. Chem. Educ. Res. Pract., 16, 758-768. https://doi.org/10.1039/C5RP00136F

[32] Albert, M. and Beatty, B.J. (2014) Flipping the Classroom Applications to Curriculum Redesign for an Introduction to Management Course: Impact on Grades. Journal of Education for Business, 89, 419-424. https://doi.org/10.1080/08832323.2014.929559

[33] Ryan, M.D. and Reid, S.A. (2016) Impact of the Flipped Classroom on Student Performance and Retention: A Parallel Controlled Study in General Chemistry. J. Chem. Educ., 93, 13-23. https://doi.org/10.1021/acs.jchemed.5b00717

[34] Cormier, C. and Voisard, B. (2018) Flipped Classroom in Organic Chemistry Has Significant Effect on Students' Grades. Frontiers in ICT, 4.

https://www.frontiersin.org/article/10.3389/fict.2017.00030

[35] Zappe, S., Leicht, R., Messner, J., Litzinger, T. and Lee, H. (2009) "Flipping" the Classroom to Explore Active Learning in a Large Undergraduate Course. Proceedings of the 2009 American Society for Engineering Education Annual Conference and Exhibition.

[36] Fautch, J.M. (2015) The Flipped Classroom for Teaching Organic Chemistry in Small Classes: Is It Effective? Chemistry Education Research and Practice, 16, 179-186. https://doi.org/10.1039/C4RP00230J

[37] Bloom, B. S., Engelhart, M.D., Furst, E.J., Hill, W.H. and Krathwohl, D.R. (1956) Taxonomy of Educational Objectives: The Classification of Educational Goals. Handbook I: Cognitive Domain. David McKay Company, New York. 